\title{
Süt Sığırı İşletmelerinin Kapasite Hesaplarının Yapılmasında Kullanılacak Android Tabanlı Bir Uygulamanın Geliştirilmesi
}

\author{
Hakkı Fırat Altınbilek $^{1}$ Ünal Kızıl ${ }^{2 *}$ \\ ${ }^{1}$ Çanakkale Onsekiz Mart Üniversitesi, Fen Bilimleri Enstitüsü, Tarımsal Yapılar ve Sulama A.B.D., Çanakkale \\ ${ }^{2}$ Çanakkale Onsekiz Mart Üniversitesi, Ziraat Fakültesi, Tarımsal Yapılar ve Sulama Bölümü, çanakkale \\ *Sorumlu yazar: unal@comu.edu.tr
}

Geliş Tarihi: 17.10.2019

Kabul Tarihi: 02.12.2019

\section{$\ddot{O} z$}

Bitkisel üretim yapılarında olduğu gibi hayvan barınaklarının projelendirilmesinde de ilk ve en önemli aşama kapasite, alan ve hacim gereksinimlerinin belirlenmesidir. Binaların boyutlandırılması, yem, gübre ve diğer girdi ve çıtıların gereksinimlerinin hesaplanması gibi işlemlerin yapılması projeleme açısından oldukça önemlidir. Bütün bu söz konusu hesaplamaların yapılabilmesi için öncelikle işletmede barındırılacak hayvanların yaş gruplarına göre sayılarının belirlenmesi gerekmektedir. Bu ise sürü kompozisyonun hesaplanmasıyla mümkündür. Sürü kompozisyonuna bağlı olarak da bina gereksinimi, kapasite hesapları, yem ve gübre depolama ihtiyaçları hesaplanabilmektedir. Bu ise özellikle fizibilite çalışmaları için önemli bir veri kaynağı oluşturacaktır. Söz konusu sürü projeksiyonu ve buna bağlı diğer kapasite hesaplarının kolayca yapılmasını sağlayacak, farklı alternatifleri kısa sürede ortaya koyacak Android tabanlı akıllı cihazlarda çalışabilecek kullanımı kolay, herkes tarafından ulaşılabilecek bir uygulama geliştirilmişstir. Geliştirilen Android uygulamada kullanılan yöntemler açıklamış ve 100 sağmal hayvana sahip bir süt sığırı işletmesi örnek olarak projelenmiştir. Sonuçlar ve uygulamanın kullanımıyla ilgili detaylar tartışılmıştır.

Anahtar Kelimeler: Süt sığırı işletmesi, barınak planlama, android programlama, akıllı cihazlar

\section{Developing an Android-based Application to be used in Capacity Calculations of Dairy Farms}

\section{Abstract}

As in other structures, the first and most important step in the design of barns is to determine the capacity, area and volume requirements. Dimensioning buildings, calculating the requirements of feed, manureand other inputs and outputs are very important for the projects. In order to carry out all these calculations, the number of animals to be housed in the enterprise should be determined according to their age groups. This is possible by calculating the herd composition. Depending on the herd composition, building requirements, capacity calculations, feed and manure storage requirements can be calculated. This will be an important data source especially for feasibility studies. An easy-to-use application that can be used by Androidbased smart devices, which will enable the herd projection and other capacity calculations to be made easily, will reveal different alternatives in a short time has been developed. The methods used in the developed Android application have been explained and a dairy cattle farm with 100 milking animals has been projected as an example. The results and details of the use of the application are discussed.

Keywords: Dairy cattle farms, livestock housing planning, android programming, smart devices

\section{Giriş}

Avrupa Birliğine adaylık sürecindeki ülkemizin mevcut işletme büyüklükleri üye ülkelerdeki işletmelerle kıyaslandığında söz konusu ülkelerle rekabet etme şansımızın olmadığı görülmektedir. Ülkemizdeki işletmelerin bu yetersizliği, ileriye yönelik kapasitelerini artırmalarına da engel olmakta ve modern barınakların kurulmalarını engellemektedir (Yaslıoğlu ve Arıc1, 2005).

Küçük aile işletmelerindeki barınakların inşasında ülkemizde genel anlamda gerekli özenin gösterilmemesinden dolayı yapısal sorunlar ortaya çıkmaktadır. Hayvanlar barınaklarda uygun koşulların sağlanamamasına bağlı olarak verim yönünden olumsuz etkilenmektedirler. Hayvanlardan elde edilen ürünlerin kalite standartlarını ve süt üretim miktarını artırmak için süt sağımıyla ilgili teknolojilere ve modern binaların yapılmasına önem verilmelidir. Batı Avrupa ülkeleri deneyimi temelinde, hayvanların sağlığı, iyi tarım uygulama kuralları ve tarımın sürdürülebilir gelişimi konuları önümüzdeki birkaç yıl içinde süt üretiminde daha da önemli hale gelecektir. Bu anlayışlara göre, sığır 
yetiştiriciliğindeki başarı ancak uygun çevresel koşulların güvence altına alınmasıyla mümkün olacaktır (Baum ve Wielicki, 2005).

Ülkemizde modern barınak sistemleri yerine yörede uygulanan barınakların taklidi şeklinde yapılan ilkel binalar üretimi olumsuz yönde etkilemektedir. Bu tür barınaklardaki hataların sonradan düzeltilmesi ise oldukça zor ve maliyetli olabilmektedir (Arıcı ve ark., 2005). Bu bağlamda, ülkemizde bundan sonra kurulacak barınaklarla ilgili olarak bir farkındalık oluşturmak için mühendislere ve üreticilere yardımcı olacak teknoloji ve yöntemlerin kullanılması faydalı olacaktır.

$\mathrm{Bu}$ teknolojilerden bir tanesi de akıllı cihazlarla uyumlu mobil uygulamalardır. Tarımsal amaçlı bu uygulamalar genelde ticaret, finans, alışveriş ve üretimde kullanılabilecek bilgilere en rahat erişim sağlayabilecek özelliklerdedir (Qiang ve ark., 2011). Bu bağlamda süt sığırcılığındaki yeni yaklaşımlar ve teknolojiler, mobil ağlar ve uygulamaları kullanmayı zorunlu kılmaktadır. Eş zamanlı olarak da mevcut bina ve makinelerin modernize edilmesi kaçınılmaz olmaktadır. Dolayısıyla yapılacak mobil uygulama çalışmaları ve yeni teknolojilerin uygulanması, iş yükünü önemli ölçüde azaltacaktır (Herbut ve ark., 2017).

Mobil teknoloji, kullanıcıların zaman ve mekân sınırlaması olmaksızın kablo vb. araç kullanmadan internet gibi genel ve özel ağlara erişmesini, veri alışverişi yapmasını ya da iletişim kurmasını kesintisiz olarak sağlayan teknoloji olarak tanımlanabilmektedir. Mobil teknolojiler denildiğinde, mobil aygıtlar, mobil işletim sistemler ve mobil internet kavramları akla gelmektedir. Günümüzde cep telefonları, akıllı telefonlar, tablet bilgisayarlar gibi taşınabilir cihazların kullanımının artmasıyla ve mobil internet erişiminin ucuzlamasıyla birlikte mobil teknolojilerin önemi de artmaktadır (Özcan, 2013). Android, mobil cihazlarda kullanılan bir işletim sistemi ve aynı zamanda akıllı telefonlar için en yaygın kullanılan uygulama geliştirme platformudur. Androidin sağladığı en önemli avantaj uygulama geliştirenler için açık kaynaklı bir geliştirme platformu sunmasıdır.

Bu çalışmada ülkemizdeki süt sığırı işletmelerinin projelenmesi aşamasında kullanılabilecek Android tabanlı mobil bir uygulama geliştirilmiştir. Geliştirilen uygulamayla yetişkin inek sayısı, buzağılama aralığı, kuruda kalma süresi, buzağı kayıp yüzdesi gibi bilgileri baz alarak farklı yaş gruplarındaki hayvan sayıları ile bir süt sığırı işletmesinde kapasiteye bağlı olarak gerekli yapı ve tesisler için alan gereksinimini hesaplamak mümkün olmuştur.

\section{Materyal ve Yöntem}

\section{Android uygulamanın geliştirilmesi}

Bu çalışmada MIT App Inventor 2 programlama ortamı kullanılarak söz konusu uygulama geliştirilmiştir. Bu ortam, akıllı telefonlar ve tabletler için tamamen işlevsel uygulamalar geliştirmeye imkan veren görsel bir programlama ortamıdır. Sağladığı en önemli kolaylık ise bulut tabanlı (cloud-based) bir geliştirme platformu olması yani programlama işleminin web tarayıcısında yapılabilmesidir.

Android uygulamaları apk uzantılı paket dosyaları şeklinde sunulmaktadır. Bu paket dosya içerisinde uygulamaya ait tüm kaynaklar (kaynak kodlar, resim dosyaları, sabit değer tanımlamaları gibi) bulunmaktadır. Android uygulamaları Java programlama dili kullanılarak geliştirilmektedir. Ancak Dalvik Virtual Machine (DVM) adı verilen bir sanal makinada yürütülmektedir (Pocatilu, 2011).

\section{Sürü kompozisyonu hesabı}

Bir süt sığırı işletmesi planlanırken ilk önce gerekli bina kapasiteleri belirlenir. Bu ise işletmenin tam kapasiteye sahip olduğunda barındırılması gereken hayvan sayısının yaş gruplarına göre hesaplanmasıyla sağlanır. Bu bağlamda sürü kompozisyonunun hesabında buzağılama aralığı, kuruda kalma süresi, buzağı kayıp yüzdesi ve gebelik oranı gibi bazı kabullerden ve anaç hayvan sayısından yararlanılır (Göncü, 2019a). Geliştirilen Android uygulamasında sağmal inek ve kurudaki ineklerin sayısı aşağıdaki formüller kullanılarak hesaplanmıştır.

$$
\begin{aligned}
& S \dot{\mathrm{I}}=\left(A_{s}-K \mathrm{I}\right)+D \\
& K \dot{\mathrm{I}}=A_{S} \times B S_{1} \\
& B S_{1}=\frac{K K S}{365} \\
& D=0.5 \times B_{A K} \times C_{D} \times Y_{123} \times G_{O} \times T_{S K}
\end{aligned}
$$


Eşitliklerde; Sİ: sağmal inek bölmesi sayısı, $A_{S}$ : sürüdeki anaç sayısı, Kİ: kurudaki inek sayısı,

D: 1. laktasyon inek say1s1, $\mathrm{BS}_{1}$ : kuruda kalma süresi katsay1s1, KKS: kuruda kalma süresi, $\mathrm{B}_{\mathrm{AK}}$ : buzağılama aralığı katsayısı, $C_{D}$ : canlı doğum oranı katsayısı, $Y_{123}$ : 0-24 aylar arası yaşama gücü, $G_{0}$ : gebelik oranı, $\mathrm{T}_{\mathrm{SK}}$ : test süresi katsayısı, $\mathrm{B}_{\mathrm{A}}$ : buzağıllama aralığı, $\mathrm{T}_{\mathrm{S}}$ : süresi. Doğum ve buzağı bölmesi kapasiteleri ise aşağıdaki eşitliklerle hesaplanmıştır.

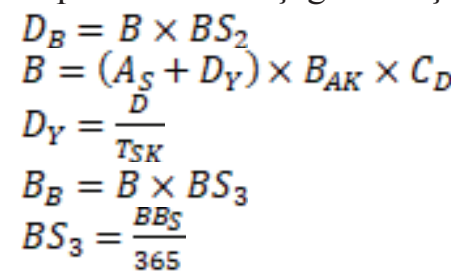

Eşitliklerde; B: bir yılda doğacak buzağı sayısı, $D_{Y}$ : bir yılda deneme ahırından geçecek inek sayısı, $\mathrm{B}_{\mathrm{B}}$ : buzağı bölmesi sayısı, $\mathrm{BS}_{3}$ : buzağı barındırma katsayısı, $\mathrm{BB}_{\mathrm{S}}$ : buzağ 1 barındırma süresi (gün).

Hesaplamalar yapılırken ilk laktasyon ineklerin verimleri dikkate alınarak 120 gün boyunca bakımı yapılıp satılacağı, erkek hayvanların da yine aynı süre sonunda besi sığırı olmak üzere satılacağı kabulü yapılmıştır. Bu bağlamda genç dişi ve erkek hayvan sayılarının hesabında aşağıdaki eşitlikler kullanılmıştır.

$$
\begin{aligned}
& G_{D D}=B \times Y_{1} \times B S_{4} \\
& G_{E D}=B \times Y_{1} \times B S_{4} \\
& B S_{4}=\frac{G H_{S}}{365}
\end{aligned}
$$

Eşitliklerde; $\mathrm{G}_{\mathrm{DD}}$ : barındırılacak genç dişi hayvan sayısı; $\mathrm{G}_{\mathrm{ED}}$ : barındırılacak genç erkek hayvan sayısı, Y1: 0-2 aylar arası yaşama gücü katsayısı, $\mathrm{BS}_{4}$ : barındırma süresi katsayısı, $\mathrm{GH}_{\mathrm{S}}$ : genç hayvan barındırma süresi (gün)

Düveler için alan hesabında kullanılacak değerler ise aşağıdaki eşitliklerle belirlenmiştir. İşletmede barındırılması gereken boğa sayısı bilgi açısından hesaplanmıştır. Ancak, günümüzde gebeliklerin suni tohumlama yoluyla gerçekleştirilmesinden dolayı boğalar için barındırma alanı hesaplanmamıştır.

$H_{D}=0.5 \times B \times Y_{2} \times B S_{5}$

$B S_{5}=\frac{G D_{S}}{365}$

$G e_{D}=0.5 \times B \times G_{O} \times Y_{3} \times B S_{6}$

$B S_{6}=\frac{G \theta D S}{365}$

$F=B \times \frac{k}{r}$

Eşitliklerde; $\mathrm{H}_{\mathrm{D}}$ : barındırılacak ham düve sayısı, $\mathrm{Y}_{2}$ : 0-6 aylar arası yaşama gücü katsayısı, $\mathrm{BS}_{5}$ : ham düve barındırma süresi katsayısı, $\mathrm{GD}_{\mathrm{S}}$ : ham düve barındırma süresi (gün), $\mathrm{Ge}_{\mathrm{D}}$ : barındırılacak gebe düve sayısı, $\mathrm{Y}_{3}$ : 0-12 aylar arası yaşama gücü katsayısı, $\mathrm{BS}_{6}$ : gebe düve barındırma süresi katsayısı, $\mathrm{GeD}_{\mathrm{S}}$ : gebe düve barındırma süresi (gün), F: barındırılacak boğa sayısı, k: bir gebelik için yeterli aşım sayısı, r: boğa başına yılda aşım sayısı. Bu eşitliklerde kullanılan katsayılar Göncü (2019a)'dan alınmıştır. Bu değerler aşağıdaki Şekil 2'de verilmiştir.

\section{Yem depolarının hesabı}

İşletmede ihtiyaç duyulacak yem depolama yapıları olarak kaba ve kesif yem depolarıyla silaj ünitesi boyutlandırılmıştır. Dikkate alınan parametreler değişik yaş gruplarındaki hayvan sayıları, bu yaş gruplarının kaba/kesif/silaj yemi gereksinimleri, bu yemlerin birim hacim ağırlıkları ve depolama süreleridir. Bu değerler kullanılarak gerekli yem hacimleri hesaplanmış, öngörülen yapı yüksekliğine bağlı olarak da gerekli taban alanları hesaplanmıştır. Yaş gruplarına göre hayvan sayıları sürü kompozisyonundan alınmıştır. Günlük yem gereksinimleri ve yemlerin birim hacim ağırlıkları varsayılan (default) değerler olarak uygulamada kullanıcıya sunulmuş ve ihtiyaç halinde değiştirme imkanı sağlanmıştır. Silaj ünitesinin boyutlandırılmasında betonarme ya da toprak altı/üstü bir ünitenin 
boyutlarının girilmesi istenmiştir. Toplam silaj hacmi gereksinimi bir ünitenin hacmine oranlanarak toplam kaç üniteye ihtiyaç duyulacağı hesaplanmıştır.

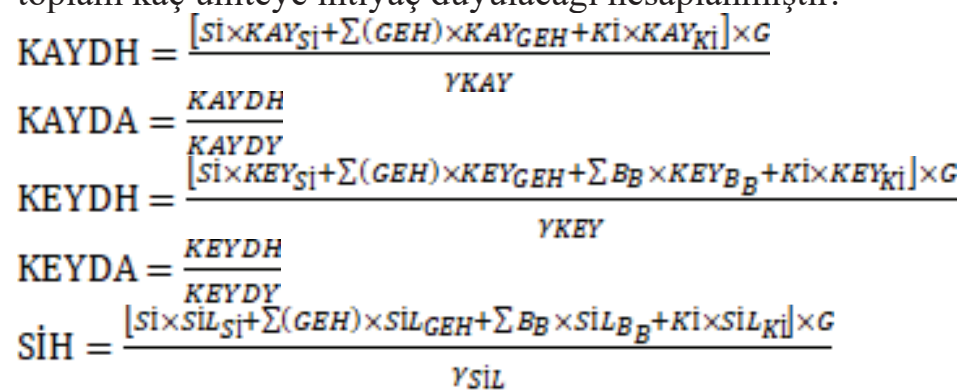

Eşitliklerde; KAYDH: kaba yem depolama hacmi $\left(\mathrm{m}^{3}\right)$, KAYDA: kaba yem depo taban alanı $\left(\mathrm{m}^{2}\right)$, KAYDY: kaba yem depo yüksekliği; KAY: günlük kaba yem gereksinimi (kg/gün); $\gamma_{\mathrm{KAY}}$ : kaba yem birim hacim ağırlı̆̆ alanı $\left(\mathrm{m}^{2}\right)$, KEYDY: kesif yem depo yüksekliği; KEY: günlük kesif yem gereksinimi (kg/gün), $\gamma_{\mathrm{KEY}}$ : kesif yem birim hacim ağırlı̆̆ $\left(\mathrm{kg} / \mathrm{m}^{3}\right)$, SİH: silaj depolama hacmi $\left(\mathrm{m}^{3}\right)$, SíL: günlük hayvan başına silaj gereksinimi ( $\mathrm{kg} / \mathrm{gün}) ; \gamma_{\text {siL }}$ : silaj birim hacim ağıllığı $\left(\mathrm{kg} / \mathrm{m}^{3}\right)$, GEH: toplam genç hayvan sayısı, G: depolama gün sayıs1.

\section{Gübre deposu hesabı}

Gübre deposu hesabında da yine değişik yaş gruplarının günlük gübre üretim miktarları $\left(\mathrm{m}^{3}\right)$ ve bu yaş gruplarındaki hayvan sayıları ve depolama süreleri dikkate alınmıştır. Ancak barınak tipinin de depo kapasitelerinde etkisi olduğu bilinmektedir. Geliştirilen uygulamada serbest duraklı ve serbest barınak tipleri dikkate alınmıştır. Serbest duraklı ahır sisteminde sağmal hayvanların gübresi ve sağımhane atıklarının betonarme gübre tankında depolanacağı, onun haricindeki kurudaki inekler, buzağılar ve genç hayvanların gübrelerinin gübre depolama yapısında depolanacağı kabul edilmiştir, Kurudaki hayvanlar ve genç hayvanların serbest sistem ahırlarda barındırılacağı dolayısıyla altlık kullanılacağ1 kabul edilmiştir. Serbest duraklı ahırlarda kauçuk altlık kullanılacağ1 öngörülmüş dolayısıyla altlık için depolama hacmi hesaplanmamıştır. Sağmal ahırının da serbest sistem olarak dikkate alınması durumunda betonarme tankın hacminin boyutlandırılmasında sadece sağımhane atıklarının hacmi dikkate alınmıştır. Betonarme gübre deposunun dairesel kesitli olacağı kabul edilmiştir. Yaş gruplarına göre günlük gübre üretim kapasiteleri MWPS (2004)'den, depoların boyutlandırılmasında kullanılan eşitlikler ise NRCS (2009)'dan alınmıştır. Gübre depolarının boyutlandırılmasında kullanılan eşitlikler Şekil 1'de verilmiştir.

\section{Doğum, hasta hayvan bölmeleri ve sağımhane hesabı}

Doğum ve hasta hayvan bölmelerinin hesabında her 25 sağmal için bir bölmenin gerekli olacağ1 ve her bölmenin $4 \times 4=16 \mathrm{~m}^{2}$ boyutlarında olacağ kabul edilmiştir (Olgun, 2016). Sağım ünitesinin boyutlandırılmasında ilk aşamada sağmal inek sayısı, ortalama süt verimi ve buna bağl1 olarak bir sağımın kaç dakikada biteceği dikkate alınarak sağım durağı sayısı hesaplanmıştır (Göncü, 2019b)

$$
\begin{aligned}
& S D_{S}=S \mathrm{I} \times \frac{S_{S}}{60} \\
& S_{S}=0.21 \times O_{S V}+2.75
\end{aligned}
$$

Sağım durağı sayısına bağlı olarak da toplanma alanı ve sağımhane boyutları belirlenmiştir. Sağımhane boyutlandırmasında kullanılan eşitlikler aşağıda verilmiştir (CIGR, 2014). Yapısal boyutlar hesaplanırken CIGR (2014)'de tavsiye edilmiş değerler dikkate alınarak sadece sağım durağı sayısı ve ortalama süt verimine bağlı olarak sağımhane boyutlandırması sağlanmıştır.

$S H_{G}=2 \times\left(S Y_{G}+G D Y_{G}+S P_{G}\right)+O A_{G}$

$S H_{U}=G K_{U}+G A_{U}+S P_{U}+D A_{U}$

$T A_{G}=2 \times\left(G D Y_{G}+S P_{G}\right)+O A_{G}$

$T A_{U}=\frac{1.4 \times S D_{S}}{T A_{G}}$

Eşitliklerde; $\mathrm{SD}_{\mathrm{S}}$ : sağım durağı sayısı, $\mathrm{S}_{\mathrm{S}}$ : sağım süresi (dak), $\mathrm{O}_{\mathrm{Sv}}$ : ortalama süt verimi (kg/gün), $\mathrm{SH}_{\mathrm{G}}$ : sağımhane genişliği $(\mathrm{m}), \mathrm{SY}_{\mathrm{G}}$ : servis yolu genişliği, $\mathrm{GDY}_{\mathrm{G}}$ : geri dönüş yolu genişliği $(\mathrm{m}) ; \mathrm{SP}_{\mathrm{G}}$ : sı ğır platformu genişliği (M), $\mathrm{OA}_{\mathrm{G}}$ : operatör alanı genişliği (m); $\mathrm{SH}_{\mathrm{U}}$ : sağımhane uzunluğu 
$(\mathrm{m}), \mathrm{GK}_{\mathrm{U}}$ : giriş koridoru uzunluğu $(\mathrm{m}), \mathrm{GA}_{\mathrm{U}}$ : giriş alanı uzunluğu $(\mathrm{m}), \mathrm{SP}_{\mathrm{U}}$ : sığır platformu uzunluğu $(\mathrm{m}), \mathrm{DA}_{\mathrm{U}}$ : dönüş alanı uzunluğu $(\mathrm{m}), \mathrm{TA}_{\mathrm{G}}$ : toplanma alanı genişliği $(\mathrm{m}), \mathrm{TA}_{\mathrm{U}}$ : toplanma alanı uzunluğu (m).

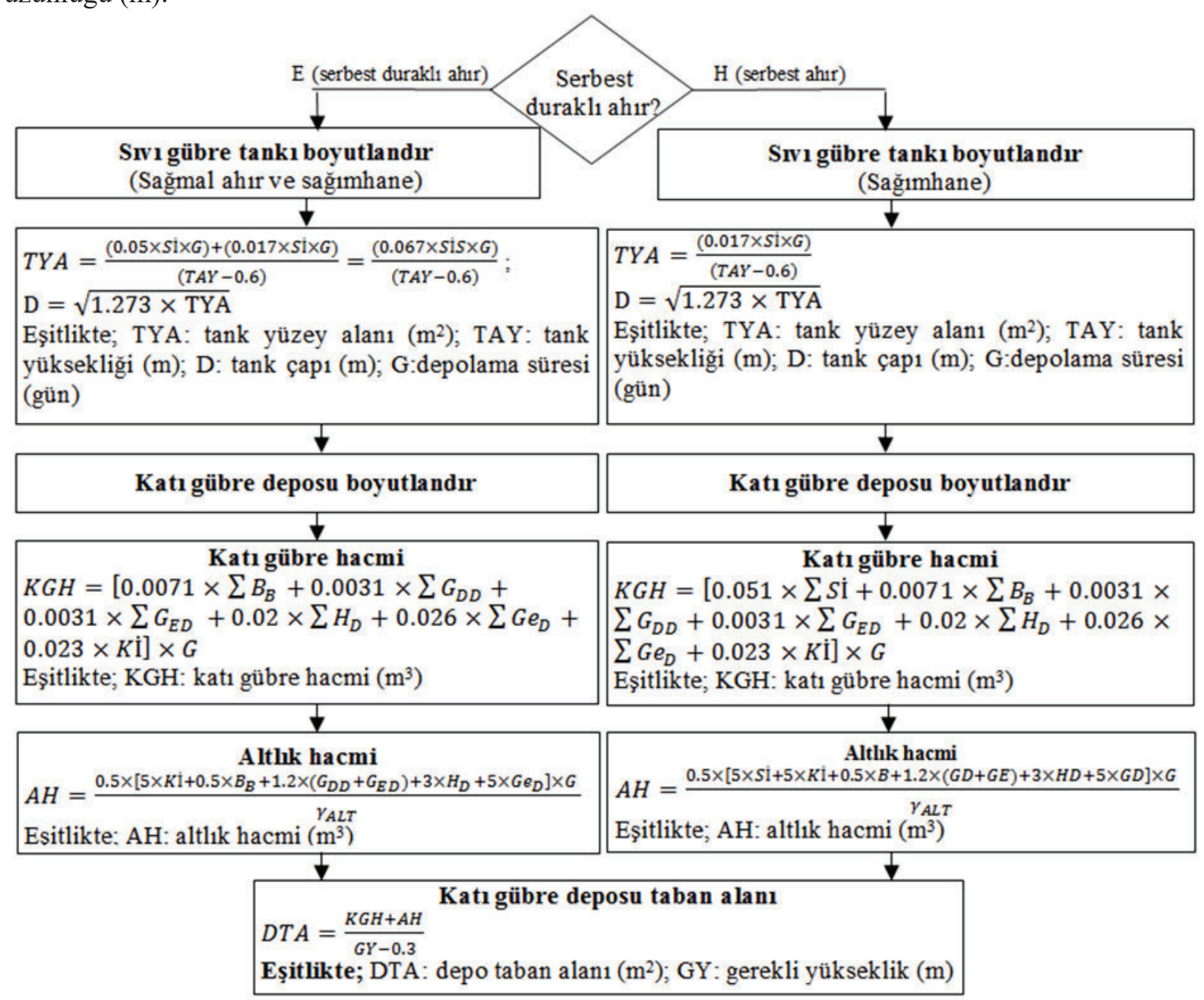

Şekil 1. Gübre depolarının boyutlandırmasında kullanılan eşitlikler ve hesap akışşeması

\section{Ahır alanlarının hesabı}

Serbest ahır boyutlandırmasında sağmal ve genç hayvanlar için Olgun (2016)'da önerilen alanlar dikkate alınmıştır. Dinlenme alanı kadar bir gezinme alanı ve gezinme alanında bırakılan yemleme alanı toplam alanı oluşturmaktadır. Serbest duraklı ahır boyutlandırmasında en önemli problem serbest duraklı sistemde servis yolu, yem yolu, durak alanları ve geçiş yollarının boyutlandırılmasının da gerekmesidir. Bu ise tasarım gerektirmektedir. Ancak geliştirilen Android uygulaması yalnızca kapasiteye bağlı olarak alanı hesabı yapmak amacıyla geliştirilmiştir. Dolayısıyla boyutlandırmanın tasarıma gereksinim duymadan matematiksel olarak hesaplanabilmesi gerekmektedir. Sağmal inek sayısına bağlı olarak serbest duraklı ahırın boyutlandırılmasında farklı kapasiteye sahip 26 serbest duraklı ahır projesi incelenmiştir. Bu projeler Midwest Plan Service (https://www-mwps.sws.iastate.edu), Penn State Extension Service (https://abe.psu.edu/extension) ve University of Tennessee Cooperative Extension Service (https://ag.tennessee.edu)'den temin edilmiştir. Sağmal hayvan sayısı ile taban alanı arasındaki doğrusal ilişkinin 0.87 'lik bir $\mathrm{R}^{2}$ değeri ve aşağıdaki eşitlikle hesaplanabildiği görülmüştür. Bu doğrusal ilişki kullanılarak yaklaşık serbest duraklı ahır taban alanı hesaplanmıştır.

$\mathrm{y}=12,251 \mathrm{x}-220,88$

Eşitlikte; y: serbest duraklı ahır taban alanı, x: sağmal hayvan kapasitesini ifade etmektedir. 


\section{Bulgular ve Tartışma}

Yukarıda özetlenmiş olan yöntem ve eşitlikler kullanılarak Android işletim sistemine sahip cihazlarda kullanılabilecek bir uygulama geliştirilmiştir. Kapasite hesaplarında kullanılan bazı varsayılan değerler kullanıcıya sunularak bir süt sığırı işletmesinde olması gereken başlıca tesislerin kapasite ve alanları yaklaşık olarak hesaplanabilmektedir. Hesaplanan bazı değerler projeleme aşamasında olduğu gibi kullanılabilmektedir. Örneğin belli sayıda sağmal hayvana sahip bir işletmedeki yem gereksinimi ve gerekli yapısal boyutlar bu uygulamadan elde edilen sonuçlar kullanılarak projelendirme yapılabilir. Ancak, serbest duraklı ahır ve sağım ünitesi tasarımında bu uygulamadan elde edilen değerler yerine işletme koşullarına göre detaylı projelendirmeler yapılarak alan gereksinimleri hesaplanmalıdır. Bunun gibi yapılar için uygulamanın sağladığı değerler yaklaşık olmakla birlikte alan gereksinimi hakkında fikir vermektedir.

Genelde süt sığırı işletmelerinde 100 sağmala sahip bir işletmenin projeleme bilgileri göz önünde bulundurularak muhtemel işletmelerin kapasite gereksinimleriyle ilgili bir fikir sahibi olmaya çalışılır. Bu bağlamda aşağıda 100 baş kapasiteli serbest ahıra sahip bir işletmenin sürü kompozisyonu belirlenerek söz konusu tesislerin kapasite ve alan gereksinimleri hesaplanmışıtır. Yukarıda da belirtildiği gibi bu hesaplar yapılırken ilk laktasyon hayvanlar 120 gün beslendikten sonra erkek hayvanların da yine aynı süre sonunda satılacağı dikkate alınmıştır. Buna göre 100 sağmala sahip bir işletmenin sürü kompozisyonu ve bu hesapta kullanılan varsayımlar Şekil 2'de verilmiştir.

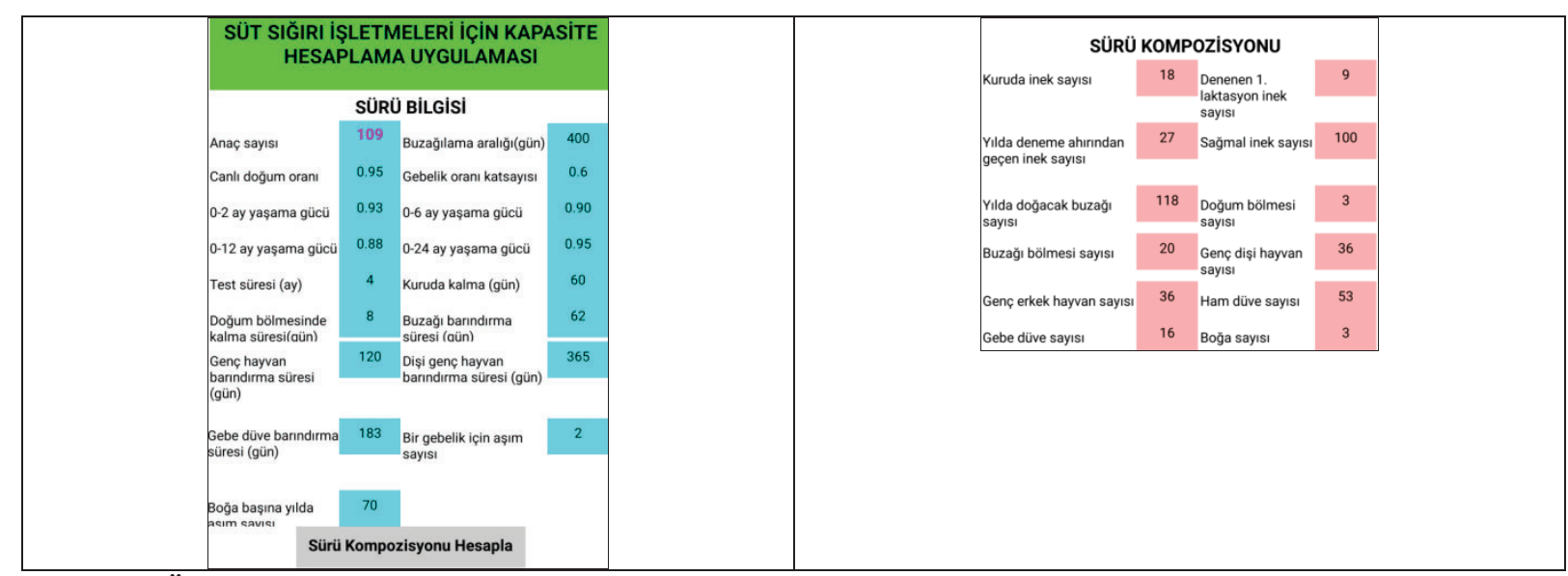

Şekil 2. Örnek sürü kompozisyonu

Görüldüğü üzere 100 sağmal hayvana sahip olabilmek için kurudaki ineklerle birlikte 118 yetişkin hayvana gereksinim duyulmaktadır. Yukarıda hesaplanmış olan hayvan sayıları dikkate alınarak kaba yem gereksinimini ve bu gereksinimi depolayabilecek yapının boyutları belirlenmiştir. Yukarıda hesaplanmış olan sürü kompozisyonuna göre 180 günlük bir depolama kapasitesi için varsayılan günlük kaba yem tüketimleri de dikkate alındığında $5 \mathrm{~m}$ yüksekliğinde bir kaba yem deposunun taban alanının $235 \mathrm{~m}^{2}$ olması gerektiği hesaplanmıştır. Varsayılan değerler değiştirilerek farkl1 alternatifler için kapasite hesaplamak mümkündür. Benzer şekilde kesif yem gereksinimi 180 günlük bir dönem için hesaplanmıştır. Uygulamanın kaba ve kesif yem hesap sonuçlarına ilişkin ekran görüntüsü Şekil 3'de verilmiştir. 


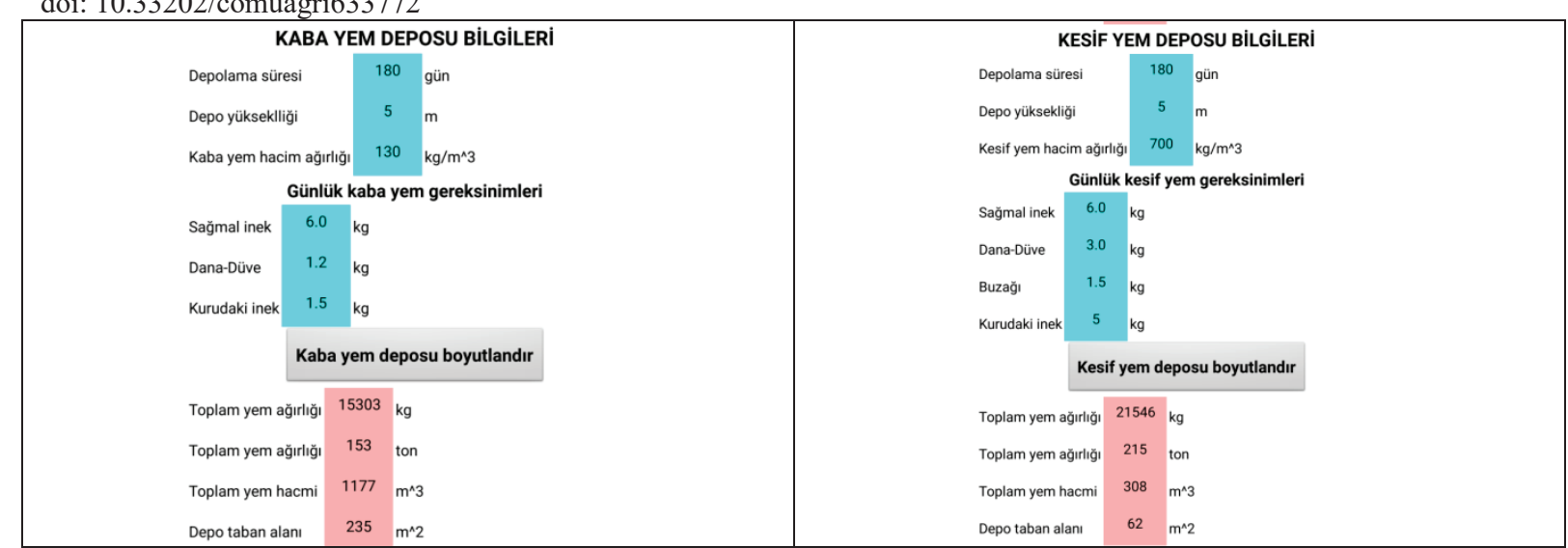

Şekil 3. Kaba ve kesif yem gereksinimi ve depolama kapasitesi

Uygulama kaba ve kesif yem haricinde silaj ünitesi kapasitesi de hesaplayabilmektedir. Yukarıda hesaplanmış olan sürü kompozisyonunun 365 günlük silaj gereksinimi, silaj ünitesi sayısı ve boyutları belirlenmiştir. Burada silaj gereksiniminin betonarme ya da toprak altı/üstü yı̆̆ınlardan karşılanacağı dikkate alınmaktadır. Bir silaj ünitesinin boyutları yukarıdaki örnekte $5 \times 12 \times 3 \mathrm{~m}^{3}$ olması durumunda yaklaşık 18 ton ve $3029 \mathrm{~m}^{3}$ lük silaj gereksinimini karşılayabilmek için bu boyutlarda 17 adet silaj ünitesine gereksinim duyulacağ olacağı hesaplanmıştır.

Gübre depolama üniteleri serbest ya da serbest duraklı olmak üzere farklı iki barınak tipi için hesaplanmıştır. Bu örnekte 90 günlük depolama süresi için serbest ahır sisteminde gerekli depolama kapasiteleri ve boyutları hesaplanmıştır. Görüldüğü üzere bu süre içerisinde $4 \mathrm{~m}$ yüksekliğe sahip bir betonarme sıvı gübre tankının yüzey alanı $45 \mathrm{~m}^{2}$ ve çap $18 \mathrm{~m}$ olarak hesaplanmıştır. Benzer şekilde katı gübre için ise $344 \mathrm{~m}^{2}$ lik bir alan gereksinimi $3 \mathrm{~m}$ yükseklik için hesaplanmıştır.

Doğum/hasta hayvan bölmelerinin tasarımı yeni bir veri girişine gereksinim duyulmamaktadır. Çünkü sağmal hayvan sayısına göre hesap yapılmaktadır. Sağımhane boyutlandırmasında ise ortalama süt verimi toplam sağım süresi bilgilerinin girilmesi istenmektedir. Buna göre örnek işletmenin silaj ünitesi, gübre depoları ve sağımhane boyutlarına ait ekran görüntüleri Şekil 4'te verilmiştir.

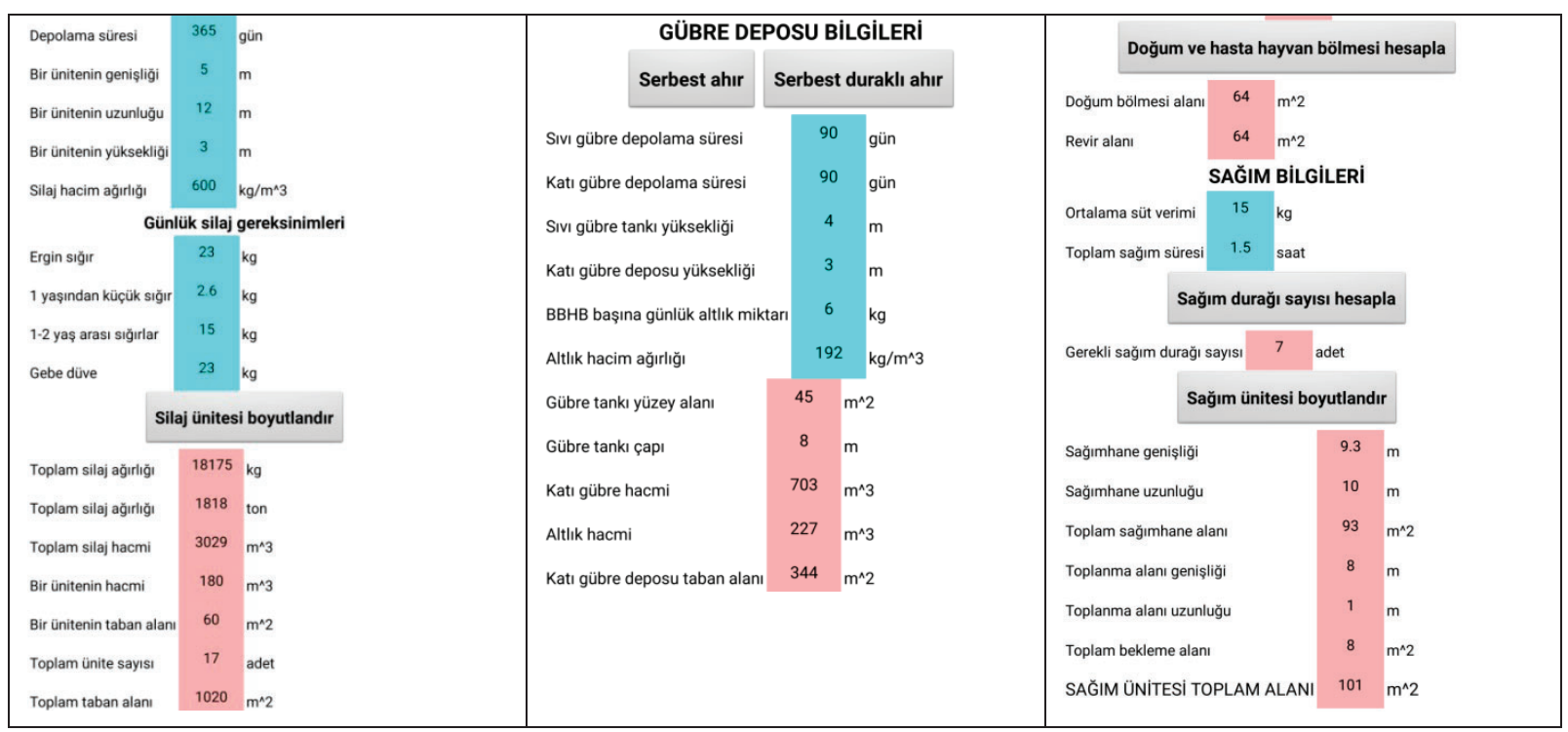

Şekil 4. Silaj ünitesi, gübre depoları ve sağımhane boyutlandırması

Uygulamada en son olarak ahırlar için alan gereksinimleri hesaplanmıştır. Görüldüğü üzere bütün yaş grupları için barınak alanları toplamı $2324 \mathrm{~m}^{2}$ olarak hesaplanmıştır (Şekil 5). Alternatif olarak serbest duraklı ahır için alan gereksinimleri güncellenmek istenirse gübre deposu hesab1 aşamasına giderek ahır tipini değiştirmek yeterli olacaktır. 


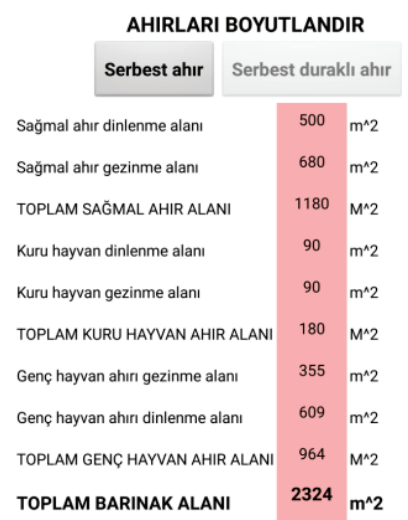

Şekil 5. Barınaklar için gerekli alanların hesabı

\section{Sonuç}

Günümüzde hayvan barınakları içinde oldukça önemli bir yere sahip olan süt sığırı işletmelerinin planlanmasında oldukça önemli problemlerle karşılaşılmaktadır. Genelde projeler taklit edilerek bilinçli bir mühendislik hesabı yapmadan işletmeler planlanmaktadır. Diğer bir konu da hayvancılıkla ilgili yatırım yapacak kişilerin ne kadarlık bir alana ve bina yatırımına ihtiyaç duyacaklarını bilmemeleri ve bu konuda sağlı bilgi alabilecekleri kaynakların çok sınırlı olmasıdır. $\mathrm{Bu}$ bağlamda geliştirilen Android uygulaması birkaç veri girişi yapılarak ahır ve diğer yardımcı tesisler için kapasite ve alanı gereksinimini hesaplama imkanı sunmuştur. Yukarıdaki örnek uygulamada konut, hangar, sosyal alanlar, yollar ve diğer tesislerin haricinde gereksinim duyulan toplam yapı alanı $4259 \mathrm{~m}^{2}$ dir. Yani 100 sağmal ineği sahip bir işletmenin 4.2 da alan sadece hayvanların barındırılması, beslenmesi ve gübrenin depolanması için gerekmektedir. Diğer alan gereksinimleriyle birlikte bu rakamın daha da artması kaçınılmazdır. Bu bağlamda geliştirilmiş olan uygulama hem fizibilite aşamasında hem projeleme aşamasında oldukça faydalı bilgilere sahip olma imkanı sunan bir akıllı cihaz uygulamasıdır.

Not: Bu makale ÇOMÜ Fen Bilimleri Enstitüsü Tarımsal Yapılar ve Sulama Anabilim Dalı Öğrencisi Hakk1 Fırat Altınbilek'in "Süt Sığırı İşletmelerinin Kapasite Hesaplarının Yapılmasında Kullanılacak Android Tabanlı Bir Uygulamanın Geliştirilmesi" isimli Yüksek Lisans tez çalışmasından türetilmiştir.

\section{Kaynaklar}

Arıcı, İ., Şimşek, E., Yaslığlu, E., 2005. Süt Sığırı Ahırlarının Planlanması. SÜTAŞ Süt Hayvancılı̆̆ı Eğitim Merkezi Yayınları, Hayvancılık Serisi:4.

Baum, R., Wielicki, W., 2005. The analysis of milk production development conditionings in Poland. Rocz. AR Pozn. CCCLXVII, Ekon. 4: 19-26

CIGR, 2014. The Design of Dairy Cow and Replacement Heifer Housing. Report of CIGR Section II Working Group No 14, Cattle Housing, 2014.

Göncü, 2019a. Süt Sığırcıllğı İşletmelerinde Gerekli Bölme Sayılarının Hesaplanması. Çukurova Üniversitesi Ziraat Fakültesi Zootekni Bölümü. http://traglor.cu.edu.tr/objects/objectFile/EchsO7Z1-303201358.pdf

Göncü s, 2019b. Sağımhane Planlamada Kullanılan Kriterler ve Sağımhane Etkenliği. Çukurova Üniversitesi Ziraat Fakültesi Zootekni Bölümü http://www.ruminantbesleme.com/sagimhane-planlamadakullanilan-kriterler-sagimhane-etkenligi/

Herbut, P., Nawalany, G., Angrecka, S., Sokołowski, P., Godyń D., 2017. A technical analysis of barns on large dairy farms in northern Poland. Nr II/2/2017, POLSKA AKADEMIA NAUK, Oddział w Krakowie, s. $837-847$

MWPS, 2004. Manure Characteristics. Midwest Plan Service. Manure Management Systems Series. Iowa State University, Ames Iowa, USA.

NRCS, 2009. Agricultural Waste Management Field Hanbook. Natural Resource Conservation Service. United States Department of Agriculture. https://www.nrcs.usda.gov/wps/portal/nrcs/detailfull/national/water/?\&cid=stelprdb1045935 
ÇOMÜ Zir. Fak. Derg. (COMU J. Agric. Fac.)

2019: 7 (2): 249-257

ISSN: $2147-8384$ / e-ISSN: 2564-6826

doi: $10.33202 /$ comuagri633772

Olgun, M., 2016. Tarımsal Yapılar, Ankara Üniversitesi. Ziraat Fak. Tarımsal Yapılar ve Sulama Bölümü, Ders Kitabı: 113-199, Yayın No: 1577, Ders Kitabı: 129.

Özcan M.,2013. Bir Android Uygulama Modeli; İstanbul Toplu Taşıma Bilgi Sistemi. Mart: İstanbul Üniversitesi Fen Bilimleri Enstitüsü

Pocatilu P., 2011. “Android applications security,” Inform. Econ., vol. 15, pp. 163-171.

Qiang, C.Z., Kuek, S.C., Dymond, A., Esselaar S. 2011. Mobile applications for agriculture and rural development. ICT Sector Unit World Bank, USA. $106 \mathrm{~s}$.

Yaslığlu, E., Arıcı, İ., 2005. Bursa bölgesinde süt sığırcılığına uygun soğuk ahır tiplerinin geliştirilmesi üzerine bir araştırma. Tekirdağ Ziraat Fakültesi Derg. 2(2): 95-114. 